\title{
Healthcare challenges of incarcerated women in Australia: An integrative review
}

\author{
Christine Stewart, Sharon L Bourke*, Janet A Green, Elianna Johnson, Ligi Anish, Miriam Muduwa, Linda K Jones \\ School of Nursing and Healthcare Professions, Federation University, Melbourne, Victoria, Australia
}

Received: June 21, 2020

Accepted: August 6, 2020

Online Published: August 25, 2020

DOI: $10.5430 /$ ijh.v7n1p10

URL: https://doi.org/10.5430/ijh.v7n1p10

\begin{abstract}
Background: Despite the rise in numbers of incarceration women, disparities between health care services and access exist. The health needs of incarcerated women is complex and influenced by multiple social determinants of health.

Purpose: Explore the healthcare issues of incarcerated women within Australian Prisons.

Methods: Integrative review of the literature.

Results: Incarcerated women represent a small proportion of the prison population within Australia, however, health outcomes are significantly impacted. Socioeconomic status, abuse (physical, emotional, sexual), previous incarceration, generational factors are some of the factors impeding the health of incarcerated women. Mental health, chronic disease conditions, maternal and child factors are significant health concerns of this vulnerable population. There is a disparity in health access and programs to improve their health outcomes. This paper explores the challenges impacting the health of incarcerated women.

Conclusions: Significant disparities exist in the access of health services available to incarcerated women. There needs to be more focus upon improving access to health services and health support programs to meet the complex health needs of incarcerated in Australia. Furthermore, there is a need for more primary health nurses to prevent and address the healthcare issues of this population.
\end{abstract}

Key Words: Incarcerated, Imprisoned women, Incarcerated mothers, Indigenous, Cultural safety, Children/incarcerated women

\section{INTRODUCTION}

The rate of incarceration of adult women has significantly risen over the last 20 years. ${ }^{[1]}$ In Australia, the average daily imprisonment rate was 218 persons per 100,000 adult population. ${ }^{[2]}$ There are a number of reasons that have contributed to this increase. One of these is social determinants of health including changes to physical and mental health, previous incarceration, and intergenerational factors such as family members previously or currently servicing time. ${ }^{[3]}$ Other social factors heightening the likelihood of incarceration of women include previous history of domestic/family violence, sexual, emotional, mental and/or physical abuse, alcohol and/or illicit drug addition, lower education levels, homelessness and low socioeconomic status. ${ }^{[3]}$

Incarcerated women are deemed the most vulnerable population within Australian prisons are incarcerated females. ${ }^{[4]}$ This vulnerable population have an increased risk of chronic conditions, communicable diseases, self-harm and a decline in mental health when compared to the general population. ${ }^{[3]}$ Incarcerated women are also a highly traumatized population resulting in the need for increased specialised health needs. ${ }^{[5]}$ It is crucial that all women within the prison sys-

\footnotetext{
*Correspondence: Sharon L Bourke; Email: s.bourke@federation.edu.au; Address: School of Nursing and Healthcare Professions, Federation University, Melbourne, Victoria, Australia.
} 
tem and wider communities have access to health services to assist in their overall health and wellbeing.

\section{METHODOLOGY AND SEARCH STRATEGY}

An integrative review methodology was utilized for this paper as it enables a broad review and facilitates a comprehensive understanding of incarcerated women in Australia. The literature was gathered using a framework outlined as Arksey and O'Malley's ${ }^{[6]}$ five step framework, and more recently Levac et al.'s ${ }^{[7]}$ method of synthesising health evidence. Relevant and recent literature was identified using Boolen phrase terms such as "Incarcerated/Imprisoned women," "incarcerated/imprisoned mothers," "Indigenous," "cultural safety," and "children/incarcerated women." The Cumulative Index of Nursing and Allied Health (CINAHL) Complete, Pubmed, Humanities Source were the databases of choice. This search identified 953 results. These terms as well as "Australia" narrowed and using only full text, peer reviewed journal articles within the last 10 years identified 56 articles of relevance. These articles made a clear link to the health care needs of incarcerated women in Australia.

\section{A PROFILE OF DISADVANTAGE}

According to the Australian Bureau of Statistics ${ }^{[2]}$ there were 43,032 prisoners nationwide with women constituting $8 \%$ (3,494 prisoners). The median age for women is 34 years with $73 \%$ born in Australia and $7 \%$ overseas. ${ }^{[2]}$ Indigenous Australian women are 21 times more likely to be incarcerated (when compared to their non-Indigenous counterparts) and are younger with a median age of incarceration at 32 years. ${ }^{[2]}$

The majority of incarcerated women in Australia have committed minor, nonviolent offences. These include: illicit drug offences (22\%), acts intended to cause injury (19\%) and unlawful entry with intent (10\%). ${ }^{[2]}$ Some women have committed serious and violent crimes which are usually against violent partners or against non-strangers. ${ }^{[8]}$ These acts intended to cause injury can be linked to domestic violence self-defense due to women enduring prolonged abuse from former partners. ${ }^{[8]}$ There is overwhelming evidence that attributes female incarceration to experiences of trauma, notably physical, sexual and/or emotional abuse as children or adults and domestic abuse. ${ }^{[9]}$ Women who have experienced childhood physical or sexual abuse are more likely to then experience domestic violence and more likely than to be incarcerated. Eighty five percent of incarcerated women have been reported as being victims of abuse. ${ }^{[8]}$

It is universally recognized that incarcerated women are considered one of the most socially, culturally and economically disadvantaged groups in Australia. ${ }^{[8]}$ The majority of these women have poor educational outcomes with most having not completed secondary schooling. ${ }^{[8]}$ Poverty is also considered a common theme in the lives of incarcerated women. Homelessness and housing insecurity, unemployment, underemployment and dependence on welfare are the results of poverty experienced in this vulnerable group. More than half the women in prison had been sleeping rough or living in short term accommodation in the month prior to being incarcerated. ${ }^{[8]}$ Those women exiting prison are also then at a greater risk of homelessness. The problem is however, that women leaving prison homeless were more than twice as likely to have returned to prison during a two year period. ${ }^{[8]}$

Difficult family backgrounds have been identified as contributors to future incarceration. ${ }^{[8]}$ More than half the incarcerated women have been in state care as well as $25 \%$ having spent time in youth prison. ${ }^{[8]}$ Incarcerated women frequently come from families who could be considered "risky," that is addicted to drugs, criminal behavior, mental health problems and prone to violence. It is important to note that this vulnerable population has a higher likelihood of poor socioeconomic living, with 15\% reported having been in prison five or more times in their life. ${ }^{[10]}$ In addition, a significant proportion of women prisoners face other challenges including intellectual or learning disability, with between $12 \%-50 \%$ living with one or both of these disabilities. ${ }^{[8]}$ Incarceration also has a wide-ranging social consequence with the majority of women being mothers of dependent children and head of a single household. ${ }^{[8]}$

The other issue here is that $40 \%$ of incarcerated women will return to prison post release; with $17 \%$ returning within 12 months and $27 \%$ within two years of release. ${ }^{[8]}$ Needless to say, imprisonment increases women's exposure to criminogenic factors and contributes to this recidivism. ${ }^{[8]}$ There are established programs within state prisons to help reduce reoffending rates. For instance, the "Better Pathways program" implemented in 2005 and Corrections Victoria "Better Pathways in Practice: The Women's Correctional Services Framework" implemented in 2007 assists in minimizing reoffending incidences, improving prison services and assist individuals once discharged ${ }^{[11]}$ It has been suggested, however, that the best way to reduce recidivism is to rehabilitate outside of prison due to the inherently criminogenic nature of the prison system. ${ }^{[8]}$ With this in mind, an intersectionality approach for mitigating the risk in successful re-entry for prisoners, is the Multiple and Complex Needs Initiative (MACNI) a specialist service in Victoria for people over the age of 16 years. ${ }^{[12]}$ This initiative provides a more effective, fair and empowering response to assist prisoners post release rather than relying on traditional disjointed individual services; it coordinates systematically between the justice, health and welfare system. ${ }^{[12]}$ 


\section{HEALTH OF INCARCERATED WOMEN}

For the prison population generally, the healthcare needs are much greater than those for the community. ${ }^{[13]}$ It follows then that the health outcomes for incarcerated women in Australia are of concern with excessive health inequalities occurring between all women within Australian prisons and the wider community. ${ }^{[15]}$ These differences can include one or more of the following: increased risk of mental illness, illicit drug or substance abuse, smoking, unsafe sexual practices, chronic illnesses and communicable diseases. ${ }^{[3]}$ Women who have increased experience of prior victimization or abuse, are more likely to then experience mental illness and this is then linked to an increased illicit drug use. It has been reported that $74 \%$ of incarcerated females have admitted to illicit drug use within the last year. ${ }^{[3]}$

Of significant concern to this vulnerable population is mental health issues. Up to $65 \%$ of incarcerated women have a history of mental illness and of those currently imprisoned, $28 \%$ were more likely to be prescribed medication to assist in treating their mental health. ${ }^{[3]}$ Mental illness mainly includes anxiety, depression, post-traumatic stress disorder, and suicide ideology. Furthermore, $31 \%$ of incarcerated women reported self-harm. ${ }^{[3]}$ Needless to say, the experience of being incarcerated itself can cause anxiety and depression, especially if the women is separated from her children.

There are also discrepancies in health service access for incarcerated women when compared to the wider community. ${ }^{[3]}$ Nationally, health services provision is regulated by an interplay between Commonwealth and State/Territory Governments with the cost of one prisoner attributing to $\$ 109,500$ per annum. ${ }^{[14]}$ In contrast, health service access for the prison system is provided by State/Territory Governments, with variation of availability of services between each prison facility. ${ }^{[3]}$ As previously highlighted, incarcerated women often have a history of homelessness, unemployment, lower level of education or come from a disadvantaged background resulting in unique health care needs. Even though there are health services available for incarcerated women, these services are often inadequate and not at the level of primary care. ${ }^{[3]}$

There are also significant limitations to incarcerated women seeking national health services. Medical and Pharmaceutical Benefits Scheme are health services controlled by the Australian Government for all Australians, however, incarcerated women are excluded from accessing this. ${ }^{[14]}$ Despite this, a staggering $70.4 \%$ of women have accessed a health professional within the last 12 months of incarceration compared to $41.9 \%$ of the general population. ${ }^{[10]}$

Discrepancies then continue following their release from 12 prison with incarcerated women experiencing severe health limitations. There is a vast array of options for professional treatment and services within the community, however not everyone has the means or affordability to access them. As a consequence often of being incarcerated, women have significant chronic health conditions. This includes cardiovascular disease (CVD), type 1 and 2 diabetes mellitus, respiratory illness (such as asthma) and arthritis. ${ }^{[3]}$ In addition, $75 \%$ of incarcerated females are smokers and illicit drug users which carry its own health issues. ${ }^{[3]}$ There are also many incarcerated women who are of increased risk of a mental health conditions that have worsened during imprisonment. ${ }^{[16,17]}$

Imprisonment reduces women's prospects of employment, increases their vulnerability to homelessness and living in a violent setting, which in turn contributes to deterioration in their emotional health, and increases their risk of minor offending. ${ }^{[8]}$ Some of the concerns and challenges experienced by women post release are the lack of appropriate and affordable housing, the lack of support for ex-prisoners with disabilities to meet parole conditions, the inaccessibility of community based alcohol and drug treatment services, and the lack of integrated mental health support during the transition from prison to the community. ${ }^{[18]}$ It has been recommended that primary prevention and reduction measures such as stable housing, employment and gender sensitive mental health are necessary key focus areas for incarcerated women. ${ }^{[19]}$

\subsection{Maternal and child health}

Incarcerated women are more likely to be parents than incarcerated men are. ${ }^{[20]}$ One of the reasons for this is that the majority of incarcerated women are of childbearing age. ${ }^{[21]}$ These women are also more likely to be single parents. ${ }^{[10]}$ It is reported that $85 \%$ of incarcerated women have been pregnant at least once and 27\% (compared to $1.6 \%$ in general population) have had 5 or more pregnancies. ${ }^{[10,21]}$ Furthermore, incarcerated women are more likely to have had a teenage pregnancy compared to women in the general population. ${ }^{[22]}$ Over half of incarcerated women had given birth to their first child during adolescence. ${ }^{[23]}$ What is of big concern, however, is the fact that incarcerated women are more likely to have accessed substances such as alcohol, illicit drugs or have been smoking during pregnancy. ${ }^{[3]}$ This has a huge ramification for not only the health and wellbeing of the women, but also on the growth and development, and more specifically neurological development of the unborn child. The long term health and wellbeing of these children may be severely affected as a consequence. ${ }^{[24,25]}$

There is limited research surrounding the antenatal health of incarcerated females. Needless to say considering the health 
issue identified earlier, incarcerated women are at greater risk of gestational diabetes, hypertension, fetal anomalies, preterm labour and birth, low birthweight baby and stillbirth. ${ }^{[21,26,27]}$ Despite this, Walker et al. ${ }^{[21]}$ found that incarcerated women did not have significantly different pregnancy outcomes compared to other similarly disadvantaged women. In contrast, however, Knight and Plugge ${ }^{[27]}$ found that when compared to similarly disadvantaged women in the general population, incarcerated women are less likely to have a low birth weight baby or stillbirth. This is suggestive of imprisonment having positive benefits for a pregnant women. After all, prison provides some safety from abusive relationships, better nutrition, and decreased intake of abusive substances. ${ }^{\text {[21] }}$ Length of time imprisoned, however is the determining factor. In the US women are more likely to stay imprisoned for longer periods, mean of 18 months ${ }^{[27]}$ compared to Australian women imprisoned around 196 to 300 days. ${ }^{[21]}$ This could help explain this anomaly in childbearing outcomes.

All eight States and Territories in Australia, except South Australia, have legal provisions that allow children to live with their mothers in prison. Women can make an application to have their baby or young child live in prison. ${ }^{[21]}$ The data related to the number of children currently living with their mothers in prison is not readily available, however approximately 13 women's prisons in Australia can accommodate children. ${ }^{[21]}$ The age of children living in prison ranges from newborn up to five years. Children over three years of age living in prison, however, is rare. ${ }^{[21]}$ New South Wales provides unique accommodation for mothers and children which is situated outside of the prison perimeter and aims to provide a safe and exclusive setting. ${ }^{[2]}$ This could be in response to the fact that one third of Australia annual births are accounted for within the prison population. ${ }^{[21]}$ Although there are standard guidelines to provide safe and effective care of children in prison, correctional agencies are reported to be ill-equipped to predict or respond to the social problems faced by women and children living in prisons. Similarly, there are a number of prisons in the UK that have specific mother baby units which have had positive outcomes in relation to decreased mental health issues and higher rates of attachment. ${ }^{[28]}$ Not all mothers, however, are able to be placed in these units. It is clear that more work needs to be undertaken in this area to facilitate better outcomes for women and their babies.

Despite these mother baby units being available in some prisons, many female prisoners will be separated from their baby after birth. It is not, therefore, surprising that there was increased use of breastmilk substitutes to feed their infant. ${ }^{[27,29]}$ Maternal incarceration undermines the critical process of attachment. ${ }^{[20]}$ It is heartening that both Hutchinson et al. ${ }^{[30]}$ and Kaminer ${ }^{[31]}$ found that bonding and attachment were con-

Published by Sciedu Press sidered to be priority concerns among incarcerated mothers. These mothers reported being concerned about separation and lack of attachment and their confidence in their mothering ability. ${ }^{[30]}$ The mothers also reflected that they thought of the baby constantly and had plans for reunification. Interesting though Kaminer ${ }^{[31]}$ found no significant difference between the level of attachment levels between 70 pregnant prisoners and 62 pregnant non-imprisoned women, though this is small sample size. Attempts to keep mother and baby together and facilitating breastfeeding can not only enhance bonding and attachment, plus the fact that breastfeeding is protective against postnatal depression ${ }^{[32]}$ and all of the advantages to the growing newborn. Keeping the mother and baby together and facilitating breastfeeding would be beneficial for mother and baby, unless the mother was on medications that were contraindicated during breastfeeding. ${ }^{[33]}$ The skin to skin contact afforded by breastfeeding can also help the baby recover from neonatal abstinence syndrome (NAS), a complication of maternal drug use seen in the baby. ${ }^{[34]}$

Women predominately are the primary carers of children when compared to men. ${ }^{[3]}$ Neither separating young children from their mother nor imprisoning the mother is ideal. The reasons cited for a baby to be removed from its mother's care in prison includes a mother who fails a drug test, experiences acute mental health problems or following a series of disciplinary issues. ${ }^{[21]}$ The risk of separation and displacement from family on children of imprisoned mothers can pose significant risk on the developmental, social and psychological needs of the infant. ${ }^{[21]}$

Children with incarcerated mothers are themselves a vulnerable group and are at risk of being placed in foster care or adoption services. ${ }^{[22]}$ Despite good intentions to provide their children with a stable family life, this does not necessarily eventuate. Unfortunately, parenting difficulties can be generational. For instance, one third of incarcerated women were placed in care as a child due to family breakdowns, abusive parents or substance abuse. ${ }^{[23]}$ In addition, many women reported frequent moves or homelessness during the six months prior to incarceration. ${ }^{[23]}$ Children of incarcerated men often remain living with their mothers, however, children of incarcerated women are more likely to have unstable living and housing arrangements. ${ }^{[20]}$ Dysfunctional and chaotic parenting is not unusual for children of incarcerated mothers. This dysfunction can stem from limited supervision and erratic discipline techniques. Furthermore, children could have lived with parents with mental illness, illicit drug and alcohol use which increases their exposure to illegal activities and violent behaviour. ${ }^{[35]}$ Poor access to appropriate health care can result in a continuation of poor health outcomes for incarcerated females and their children 
which has a tendency to be perpetuated to the next generation and so the cycle continues.

A significant number of children have experienced, or are experiencing, maternal incarceration. ${ }^{[20]}$ Children with incarcerated mothers risk developmental, emotional, social and psychological adversity. ${ }^{[35]}$ Child and family health nurses represent a resource to provide support, growth and development surveillance, health promotion, education and clinical services for families with young children. ${ }^{[20]}$ With the input of child and family health nurses, maternal incarceration does not have to lead to negative outcomes for children. Child and family health nurses who are engaged with the prison system can provide opportunities for mothers to participate in education and other programs to develop mothering and parenting skills. ${ }^{[20]}$ The provision of parenting support can help incarcerated mothers reintegrate into the community and provide developmental and surveillance opportunity and referral for early intervention if required. ${ }^{[20,28]}$

\subsection{Indigenous health}

There is an over representation of Aboriginal women in the prison population. For instance, in NSW 30\% of women in prison are Aboriginal compared to being only $2 \%$ of the general population. ${ }^{[21]}$ More than $80 \%$ of incarcerated Aboriginal women are also mothers, and many also have primary care responsibilities for children and their extended families. ${ }^{[36]}$ Of these Aboriginal women in prison, 59\% reported significant morbidity attributed to three or more of the following conditions: kidney disease, asthma, bronchitis, migraines, diabetes mellitus, hypercholesterolemia and cancer. ${ }^{[36]}$ In addition, it is reported that $91 \%$ of Aboriginal women required prescription medication. ${ }^{[36]}$ Furthermore, infectious disease prevalence is high in this population including Hepatitis $\mathrm{B}$ and Hepatitis $\mathrm{C}$ rates. ${ }^{[36]}$ Aboriginal women are also at higher risk of mental health issues and more likely to have been victims of violence. ${ }^{[37]}$ The relationship between prior history of childhood physical and sexual abuse and mental health illness equally applies here as identified earlier. It has been suggested that a major factor impacting on Aboriginal women's mental health is stress and anxiety attributed to family and children whilst incarcerated. ${ }^{[36]}$ The mental health of incarcerated Indigenous Australians is also impacted by historical outcomes, intergenerational trauma, racism, discrimination, political inequities and trauma which compounds the childhood abuse these women may have experienced and the resultant mental health issues. ${ }^{[36,38]}$ Incarcerated Aboriginal women's health needs are, therefore, complex.

Although the "Equal Treatment Principle" based on providing the same standard of treatment as non-prison population is used in Australia, health inequities exist between
Indigenous and non-Indigenous populations during incarceration. ${ }^{[36]}$ It is clear that there is a significant lack of funding to medical services and culturally sensitive care support programs for Indigenous women. There is an urgent need, therefore, for culturally sensitive health care to Indigenous women during incarceration as poor access to mental and medical services is attributed to high rates of suicide and drug overdose immediately post release. ${ }^{[39]}$

\section{THE PROVISION OF HEALTH SERVICES}

The programs to assist the health and wellbeing of incarcerated women differ between private and public health providers. There are no national standards for measuring the type and quality of services and outcomes for prison care in Australia, ${ }^{[40]}$ resulting in substantial gaps in evidence to advocate for service delivery change. ${ }^{[36]}$ It is reported that prisons in Australia were operating at $116 \%$ design capacity during 2017-2018 resulting in further constraints in access health care. ${ }^{[3]}$ Dependent on location, the provision of health services and practitioners is determined by local government or the Department of Justice or Corrections. ${ }^{[3,36]}$ The provision of hospital or specialised health care services that are offered in female prisons are dependent on the size of the prison, population and jurisdiction. ${ }^{[3]}$

Security considerations and specific State and Territory Government Law restrict services offered to incarcerated women. In most communities, an individual suffering from mental health problems would seek General Practitioner services and referrals to mental health professionals; these services are not readily available within prisons. ${ }^{[3]}$ Upon arrival to prison, incarcerated women may find difficulty in continuing current treatment regimes. This is because a prisoner must seek out health services willingly to receive appropriate treatment. Prisoners have reported that seeking health care is not a priority for them (63\%) or was too expensive (38\%) and hence the reasons for not accessing this service. ${ }^{[10]}$ This may then cause delays in their prescribed treatment or medication/s, thus prolonging time frames in accessing their medical information, and medication accessibility. ${ }^{[3]}$ The lack of funding for treatment and medications can ultimately place the individual at further risk to their health and well-being. Ineligibility to Medicare and the Pharmaceutical Benefits Scheme (PBS) impacts heavily on mental health pharmacology accessibility unless pre-approval has been given by the Minister for Health. ${ }^{[3,15]}$ This is of concern as prisoners were 9 times more likely to be prescribed an antipsychotic, 2 times more to be prescribed anti-depressants and 4 times more to be prescribed a medication to assist an addiction then those living within the community. ${ }^{[3]}$ Despite the fact that mental health is a major theme within the health outcomes 
of all incarcerated women, there is a clear lack of mental health services available. Furthermore, the biggest issue for women with mental health issues is that prison health services are based around men and their mental health needs. As previously mentioned, women have high experiences of trauma which requires appropriately targeted mental health management. In addition, if the women is Aboriginal, there is a lack of culturally sensitive care support programs as well as medical services for these women. There is an urgent need to address this deficit.

Nurses have a responsibility to advocate for the health of incarcerated women within Australian prisons. As previously identified, mental health is a major health concern impacting incarcerated women. The problem is that there is generally a lack of primary healthcare nursing services available in prisons to be able to address the primary healthcare needs of this population. ${ }^{[13]}$ There are attempts to address this deficit through the implementation of a "Wellbeing clinic for women's mental health" program. This is similar to the "Men's Health and Wellbeing Clinic" implemented at Barwon Men's Prison which may significantly aid in meeting the mental health needs of incarcerated women. ${ }^{[41]}$ In formulating programs based upon the Barwon Prison model; the role of the nurse in these programs would be designed to help to build understanding of female health issues, improve the health systems responsiveness to women's needs, strengthening preventative health interventions targeting women and focusing attention on priority health conditions of incarcerated women. ${ }^{[42]}$

There are a number of recommendations that is evident from this review. More separate units for women and their babies would assist in achieving the necessary attachment and bonding and the positive effects this has. Strengthen women's resilience through participation in community work or vocational and educational opportunities. Healthcare services need to be more focused on primary healthcare of incarcer-

\section{REFERENCES}

[1] Riley BJ, Smith D, Baigent MF. Mindfulness and acceptance-based group therapy: An uncontrolled pragmatic pre-post pilot study in a heterogeneous population of female prisoners. International Journal of Offender Therapy and Comparative Criminology. 2019; 63(15-16): 2572-2585. PMid:31238758. https://doi .org/10.1177/0306 $624 \times 19858487$

[2] Australian Bureau of Statistics (ABS). Prisoners in Australia, Aboriginal and Torres Strait Islander prisoner characteristics. At 30 June 2019. Available from: https://www . abs .gov . au/ausstat s/abs@.nsf/Lookup/by\%20Subject/4517.0 2019 Main\%20

Published by Sciedu Press ated women to help prevent many of the healthcare issues that women have. ${ }^{[13]}$ There is also a need to break the intergenerational cycle of incarceration that tends to occur with women through prevention of the initial trauma and abuse that occurs and supporting women to transition through this. In addition, there is a need for targeted trauma informed psychosocial support programs for women with history of abuse to help break the cycle, especially for Aboriginal women and culturally sensitive healthcare. Finally, there is a need for more research into incarcerated women, especially Aboriginal women, further identifying healthcare needs and evaluating healthcare programs in meeting these needs.

\section{Conclusion}

The health of incarcerated women within Australian prisons is a significant health concern. Multiple factors impact on the health and wellbeing of incarcerated women including low socioeconomic states, mental health considerations, domestic violence, abuse, alcohol and illicit drug use and homelessness. There is a high prevalence of chronic health conditions within this vulnerable group, however, there is disparity between health care access and provision to incarcerated females which significantly impacts on their health and wellbeing during incarceration and post release. There is a need to improve the health service access as well as the development of health related programs to assist in improving the overall health outcomes of incarcerated women. Further research is needed into the primary healthcare needs of these women and the provision of primary healthcare nursing services.

\section{ACKNOWLEDGEMENTS}

The primary author would like to thank the academics at Federation University for the support in putting this article together.

\section{CONFlicts of InTEREST Disclosure}

The authors declare that there is no conflicts of interest.
Features $\sim$ Aboriginal\%20and\%20Torres\%20Strait\%20Isla nder $\% 20$ prisoner $\% 20$ characteristics $\% 20 \sim 13$

[3] Australian Institute of Health and Welfare (AIHW). The health of Australia's Prisoners. 2018. Available from: https://www .aihw.gov.au/reports/prisoners/heal th-australia-prisoners-2018/data

[4] Queensland Government. Improving outcomes for incarcerated women. 2019. Available from: https://corrections.qld.go v. au/improving-outcomes-for-incarcerated-women/

[5] Karlsson ME, Zielinski MJ. Sexual Victimization and Mental Illness Prevalence Rates Among Incarcerated Women: A Litera- 
ture Review. Trauma, Violence and Abuse. 2020; 21(2): 326-349. https://doi.org/10.1177/1524838018767933

[6] Arksey H, O’Malley L. Scoping studies: towards a methodological framework. International journal of social research methodology. 2005; 8(1): 19-32. https://doi.org/10.1080/136455703200 0119616

[7] Levac D, Colquhoun H, O'Brien KK. Scoping studies: advancing the methodology. Implementation science. 2010; 5(1): 69 PMid:20854677. https ://doi .org/10.1186/1748-5908-5-6 9

[8] Kilroy D. Women in Prison in Australia Panel Presentation by Debbie Kilroy (Sisters Inside (CEO) and Principal of Kilroy and Callaghan Lawyers ) Current Issues in Sentencing Conference (National Judicial College of Australia and the ANU College of Law) 6-7 February 2016 Australian National University, Canberra.

[9] Gleeson H, Baird J. Why are our prisons full of domestic violence victims? ABC News. 2018. Available from: https : //www . abc.net . au/news/2018-12-20/womens-pri sons-full-of-domestic-violence-victims/10599232

[10] Coopes A. New report sheds stark light on prisoner health. 2019. Available from: https://croakey.org/new-report-sheds-s tark-light-on-prisoner-health/

[11] Australian Institute of Criminology. Good practice in women's prisons: A literature review. 2011. Available from: https://aic.gov $\mathrm{au} / \mathrm{publications/tbp/tbp041}$

[12] Bunn R. Intersectional needs and re-entry: Re-conceptualizing 'multiple and complex needs' post release. Criminology \& Criminal Justice. 2019; 19(3): 328-345. https : //doi.org/10.1177/1748895817 751828

[13] Condon L, Hek G, Harris F. A review of prison health and its implications for primary care nursing in England and Wales: the research evidence. Issues in Clinical Nursing. 2007; 16: 1201-1209. PMid:17584337. https ://doi.org/10.1111/j.1365-2702.20 $07.01799 . x$

[14] Bushnell A. Australia's Criminal Justice Costs: An International Comparison. Institute of Public Affairs. 2017. Available from: https://ipa.org.au/wp-content/uploads/2017/08/IPA -Report-Australian-Criminal-Justice-Costs-An-Inter national-Comparison.pdf

[15] Plueckhahn TM, Kinner SA, Sutherland G, et al. Are some more equal than others? Challenging the basis for prisoners' exclusion from Medicare. Medical Journal of Australia. 2015; 203(9): 359-361. PMid:26510802. https ://doi.org/10.5694/mja15.00588

[16] Harner HM, Riley S. The impact of incarceration on women's mental health. Qualitative Health Research. 2012; 23(1): 26-42. PMid:23034774. https : //doi .org/10.1177/10497323124614 52

[17] Spittal MJ, Forsyth S, Pirkis J, et al. Suicide in adults released from prison in Queensland, Australia: a cohort study. Journal of Epidemiology and Community Health. 2014; 68(10): 993-998. PMid:25009152. https://doi.org/10.1136/jech-2014-204295

[18] Victorian Ombudsman (VO). Investigation into the rehabilitation and reintegration of prisoners in Victoria. Victorian Government Printer. 2015.94 p.

[19] Anderson R. Spotlight on incarceration and women's health. 2018 Available from: https://womenshealthvic.com.au/resourc es/WHV_Publications/Spotlight_2018.09.27_Spotlight -on-incarceration-and-womens-health_Sep-2018-updat e-Feb19_(Fulltext).pdf

[20] Rossiter C, Power T, Fowler C, et al. Mothering at a Distance: what incarcerated mothers value about a parenting programme.
Contemporary Nurse. 2015; 50(2-3): 238-255. PMid:26453380. https://doi.org/10.1080/10376178.2015.1105108

[21] Walker JR, Baldry E, Sullivan EA. Residential programmes for mothers and children in prison: Key themes and concepts. Criminology \& Criminal Justice. 2019; 1-19. https ://doi .org/10.1177/1748 895819848814

[22] Liotta M. Majority of women in prison are mothers: Report. 2019. Available from: https://www1.racgp.org.au/newsgp/clini $\mathrm{cal} / \mathrm{maj}$ ority-of-women-in-prison-have-dependent-chi Idren

[23] Indig D, McEntyre E, Page J, et al. 2009 NSW inmate health survey: Aboriginal health report. 2010. Available from: https://www . justicehealth.nsw.gov.au/publications/ 2015NPHSReportAboriginalPeoplesHealthReport.pdf

[24] Machaalani R, Ghazavi E, Hinton T, et al. Cigarette smoking during pregnancy regulates the expression of specific nicotinic acetylcholine receptor subunits in the human placenta. Toxicol Appl Pharmacol. 2014; 276(3): 204-212. PMid:24607864. https ://doi .org/10.1 016/j.taap. 2014.02.015

[25] Reid N, Gamble J, Creedy DK, et al. Benefits of caseload midiwfery to prevent fetal alcohol spectrum disorder: a discussion paper. Women and Birth. 2019; 32(2019): 3-5. PMid:29602689. https://doi.org/10.1016/j.wombi.2018.03.002

[26] Cordero L, Hines S, Shibley KA, et al. Perinatal outcomes for women in prison. Journal of Perinatology. 1992; 12(3): 205-209.

[27] Knight M, Plugge E. The outcomes of pregnancy among imprisoned women: a systematic review. British Journal of Obstetrics and Gynaecology. 2005; 112(11): 1467-1474. PMid:16225564. https://doi.org/10.1111/j.1471-0528.2005.00749.x

[28] Dolan R, Shaw J, Hann M. Pregnancy in prison, mother and baby unit admission and impact on perinatal depression and quality of life. Journal of Forensic Psychiatry and Psychology. 2019; 30(4): 551-569. https://doi.org/10.1080/14789949.2019.1627482

[29] Chambers A. Impact of forced separation policy on incarcerated postpartum mothers. Policy, Politics, \& Nursing Practice. 2009; 10(3): 204-211. PMid:20022914. https ://doi.org/10.1177/152715 4409351592

[30] Hutchinson KC, Moore GA, Propper CB, et al. Incarcerated women's psychological functioning during pregnancy. Psychology of Women Quarterly. 2008; 32: 440-453. https://doi.org/10.1111/j.14 71-6402.2008.00457.x

[31] Kaminer A. Women in prison: study looks at life, maternal feelings. Correct Care. 1992; 6: 3.

[32] Pope CJ, Mazmanian D. Breastfeeding and postpartum depression: an overview and methodological recommendations for future research. Depression research and treatment. 2016. PMid:27148457. https : //doi.org/10.1155/2016/4765310

[33] Davanzo R, Copertino M, De Cunto A, et al. Antidepressant drugs and breastfeeding: a review of the literature. Breastfeeding Medicine. 2011; 6(2): 89-98. PMid:20958101. https ://doi.org/10.1089/ bfm. 2010.0019

[34] Paynter MJ, Drake EK, Cassidy C, et al. Maternal health outcomes for incarcerated women: A scoping review. Journal of Clinical Nursing. 2019; 28(11-12): 2046-2060. PMid:30786097. https : //doi.org/10.1111/jocn.14837

[35] Dawson A, Jackson D, Nyamathi A. Children of incarcerated parents: Insights to addressing a growing public health concern in Australia. Children and Youth Services Review. 2012; 34(12): 2433-2441. https://doi.org/10.1016/j.childyouth.2012.09.003

[36] Kendall S, Lighton S, Sherwood J, et al. Incarcerated aboriginal women's experiences of accessing healthcare and the limitations of the 'equal treatment' principle. International Journal for Equity in 
Health. 2020; 19: 48. PMid:32245479. https://doi.org/10.118 6/s12939-020-1155-3

[37] Sherwood J, Kendall S. Reframing spaces by building relationships: community collaborative participatory action research with Aboriginal mothers in prison. Contemporary Nurse. 2013; 46(1): 83-84. PMid:24716766. https://doi.org/10.5172/conu.2013.46.1 .83

[38] Stanley E. Human Rights and Incarceration - Critical Explorations. 2018. https://doi.org/10.1007/978-3-319-95399-1

[39] Heffernan EB, Andersen KC, Dev A, et al. Prevalence of mental illness among Aboriginal and Torres Strait Islander people in Queens- land Prisons. Medical Journal of Australia. 2012; 197(1): 46-49. PMid:22762230. https://doi.org/10.5694/mja11.11352

[40] Public Health Association Australia. Public Health Association of Australia: Prisoner health background paper. 2017. Public Health Association Australia: Canberra.

[41] Australian Primary Health Care Nurses Association (APNA). (2017) Case studies - Men's health and wellbeing clinic. 2017. Available from: https://www.apna.asn.au/nursing-tools/nurse-c linics/case-studies/clinic-5

[42] State Government of Victoria. Improving men's health and wellbeing. 2013. Available from: www.health.vic.gov.au/diversity/me $\mathrm{n}$ 